\title{
Effectiveness of dynamic pricing strategy in presence of supply chain disruptions
}

\section{Tedarik zinciri kesintilerinde dinamik fiyatlama stratejisinin etkinliği}

\author{
Mualla GONCA AVCI ${ }^{*}$ iD \\ ${ }^{1}$ Department of Industrial Engineering, Engineering Faculty, Dokuz Eylul University, Izmir, Turkey. \\ gonca.yunusoglu@deu.edu.tr
}

Received/Geliş Tarihi: 10.09.2019

Revision/Düzeltme Tarihi: 06.01.2020

doi: $10.5505 /$ pajes.2020.54077

Accepted/Kabul Tarihi: 15.02.2020

Research Article/Araștırma Makalesi

\begin{abstract}
The severe impacts of disruptive events on real-world supply chains have attracted the researcher's attention on supply chain disruptions in the last decade. In the related literature, several strategies aimed at reducing the impact of disruptions have developed and analyzed. However, there exists no study which analyzes the effectiveness of pricing strategies in presence of disruptions on real-world supply chains to the best of our knowledge. Within this scope, a dynamic pricing approach is developed to mitigate stock-out risks aroused from disruptions. The rationale behind the proposed approach is to channel customer demand from a scarce product to a substitute product. The proposed approach is implemented in a retail supply chain. The computational results confirm the effectiveness of the dynamic pricing policy in the presence of disruptions.
\end{abstract}

Keywords: Supply chain disruptions, Dynamic pricing, Simulation.

\section{Introduction}

Supply chain disruption is the outcome of a process whereby one or more adverse events taking place at a particular location in a supply chain which impact on the performance of one or more locations in the supply chain. Causes of supply chain disruptions may be natural disasters, demand shifts, supplier problems, human/organizational behavior, information technology problems, financial problems, and regulatory problems [1]. As supply chain disruptions have huge impacts on costs and service levels, they can pose a threat on competitive advantage on organizations. For example, Ericsson lost $\$ 400$ million in potential revenues due to a fire at its major supplier.

The bad experiences of large companies about disruptive events have attracted researchers' attention on supply chain disruptions recently. In the last decade, several studies which develop models for disruptive events and their consequences, and mitigation strategies are published. In this context, a number of strategies against disruptions have been developed such as holding buffer inventory [2], sourcing flexibility [3], adaptive ordering [4], and back-up capacity [5]. For a comprehensive review of the related literature, the reader may refer to [6],[7], and [8].

The related literature lacks a quantitative study which employs the dynamic pricing strategy against disruptions. Besides, the widely known Dell case [9] demonstrates the benefits of an effective pricing strategy on mitigating supply chain disruption
Öz

Yıkıcı olayların gerçek hayat tedarik zincirleri üzerindeki etkileri son on yılda araștırmacıların dikkatini tedarik zinciri kesintileri üzerine çekmiștir. İlgili yazında kesintilerin etkilerini azaltmayı amaçlayan birçok strateji geliştirilmiş ve analiz edilmiştir. Ancak, fiyatlandırma stratejilerinin kesintiler altındaki etkinliğini gerçek tedarik zincirleri üzerinde analiz eden herhangi bir çalışma bildiğimiz kadarıyla bulunmamaktadır. Bu kapsamda, kesintilerden kaynaklanan stok açlığı riskini azaltmak için bir dinamik fiyatlandırma yaklașımı geliștirilmiştir. Önerilen yaklaşımın arkasındaki mantık, müşteri talebini az bulunan bir üründen ikame bir ürüne yönlendirmektir. Önerilen yaklaşım bir perakende tedarik zincirine uygulanmıștır. Hesaplamalı sonuçlar, dinamik fiyatlandırma politikasının kesintilerin varlığındaki etkinliğini ortaya koymuştur.

Anahtar kelimeler: Tedarik zinciri kesintileri, Dinamik fiyatlama, Benzetim.

risks. During a few weeks after Taiwan earthquake in 1999 , several component suppliers of Apple and Dell could not deliver computer components. To deal with the component shortages, Apple tried to convince its customers to buy a slower version of G4 computers. However, this strategy provoked severe customer complaints. On the other hand, Dell offered special prices to steer its customers to the computers with the components supplied from other countries instead of alerting them about the component shortages. The pricing strategy improved the earnings of Dell by $41 \%$ in 1999 despite the supplier disruption [10].

In the related literature, there are a few studies that consider pricing strategies in presence of disruptions. Zhu [11] derived optimal policies for replenishment, production and pricing in presence of supply disruptions and demand uncertainty. Gong, Chao [12] characterized the optimal ordering and pricing policies for a dual sourcing system with disruptions and random price-sensitive demand. Huang, He [13] developed a Stackelberg model in presence of production disruptions for a food supply chain to obtain inventory, pricing and preservation decisions. Ghomi-Avili, Naeini [14] proposed a fuzzy biobjective, bi-level model by considering a price-dependent demand for a competitive supply chain under disruptions. Huang, Wang [15] analyzed the impact of disruptions on equilibrium pricing and production decisions in a closed-loop supply chain in which the manufacturer licenses the third party for remanufacturing activities. Hosseini-Motlagh et al. [16] derived the optimal pricing, corporate social responsibility and

${ }^{*}$ Corresponding author/Yazışılan Yazar 
sustainability decisions by considering demand disruptions for centralized and decentralized reverse supply chain systems. Hou et al. [17] addressed a joint problem consisting of hub location and revenue management problem in airline networks by considering disruptions. Rahmani, Yavari, [18] analyzed pricing and greening decisions in a dual-channel green supply chain with demand disruptions for centralized and decentralized cases.

The unique study which considers pricing as a mitigation strategy against disruptions is [19]. Bugert and Lasch [19] extended the system dynamics model developed by Wilson [20] with responsive pricing. Our study differs from the aforementioned studies in its generalizability to more than two products and consideration of customers' willingness to pay. Moreover, there exists no real-world case study employing dynamic pricing for disruption risk mitigation to the best of author's knowledge.

In this study, a dynamic pricing strategy concerning inventory levels is applied to a multi-commodity supply chain system in presence of disruptions. A disruption in supply of a product can cause shortages in finished goods inventory which diminish service levels of the supply chain. To overcome a potential shortage, a dynamic pricing policy is employed to channel demand from a scarce product to a substitute product. In particular, dynamic pricing policy sets higher prices to scarce products so that demand for the scarce products can shift to substitute products. The performance of proposed approach is tested on a real-world supply chain. The simulation results reveal that dynamic pricing is a promising mitigation strategy against supply chain disruptions.

The rest of the paper is structured as in the following. In Section 2 , the problem addressed in this study is described. In Section 3 , we give detailed information related with the real-world application, and explain the simulation model. In Section 4, the computational study is presented. Finally, conclusive remarks and future research directions are provided in Section 5.

\section{Problem description}

This paper addresses a supply chain planning problem with disruptions and dynamic pricing. In this context, we consider a wholesaler selling multiple types of product to several retailers. The retailers place orders to the wholesaler on daily basis. The wholesaler fills the retailers' orders from its on-hand inventory. The wholesaler adopts an order up-to-level policy, and places orders to manufacturers on each day. The manufacturers deliver the orders of the wholesaler after a transportation lead time. However, the manufacturers are vulnerable to disruptive events, such as labor strikes, border closings, natural disasters and economic crises. Occurrence probabilities and severities of the disruptive events cannot be predicted. During a disruption, a manufacturer loses a part of its shipment capacity. The amount of the lost capacity depends on the severity of the disruptive event. When the disruption is over, the manufacturer recovers its shipment capacity gradually. If the shipment capacity of the manufacturer is insufficient to fill the wholesaler's order, the manufacturer backorders the order to fill it in the next period.

Daily operations of the wholesaler in a typical period are depicted in Figure 1. At the beginning of the day (see Step (1) in Figure 1), inventory level of the wholesaler for each product is updated by considering the deliveries received. It is assumed that deliveries are received at the beginning of the period before the customer demand is realized.

Formally, the inventory level of the wholesaler for each product at the beginning of period $t$ is calculated as in Eq. 1 .

$$
I_{b}(i, t)=I_{e}(i, t-1)+D(i, t)
$$

Where $I_{b}(i, t)$ is the inventory level of product $i$ at the beginning of period $t, I_{e}(i, t-1)$ is the inventory level of product $i$ at the end of period $t-1$, and $D(i, t)$ is the amount of delivery of product $i$ received at period $t$.

Once the inventory levels are updated, the wholesaler specifies its requirement for each product (see Step (2) in Figure 1). The amount required is calculated by considering updated inventory levels and customer demand forecast. Customer demand forecast is determined based on historical demand information. Herein, several statistical forecasting methods can be employed depending on the customer demand pattern. For a stable customer demand without trend and seasonality, simple exponential smoothing method is a suitable forecasting method. In this study, the supply chain faces a high and stable customer demand. Therefore, the simple exponential smoothing method is employed to obtain demand forecasts (Eq. 2).

$$
C(i, t)=\theta C(i, t-1)+(1-\theta) C(i, t-1)
$$

Where $C(i, t)$ is the demand forecast for product $i$ at period $t$ , $\theta \in[0,1]$ is the smoothing parameter, and $C(i, t-1)$ is the amount of demand for product $i$ at period $t-1$.

The amount of order placed by the wholesaler for product $i$ at period $t, O(i, t)$, is calculated as follows:

$$
O(i, t)=\max \left\{0,\left[\gamma C(i, t)-I_{b}(i, t)-B(i, t)\right]\right\}
$$

Where $\gamma$ is the inventory adjustment parameter, and $B(i, t)$ is the amount of order placed by the manufacturer which is backordered at period $t$.

The order placed at period $t$ is delivered at the next period as long as the manufacturer's available shipment capacity is sufficient. However, the manufacturer's available shipment capacity is uncertain due to disruptive events. If the current available capacity is insufficient to meet the wholesaler's order, the unfilled portion of the order is backordered. The amounts of delivery and backorder at the next period are specified as in Eq. 4 and 5, respectively.

$$
\begin{gathered}
D(i, t+1)=\min \{[O(i, t)+B(i, t)], S(i, t)\} \\
B(i, t+1)=\max \{0,[O(i, t)+B(i, t)-S(i, t)]\}
\end{gathered}
$$

Where $S(i, t)$ is the available shipment capacity of the manufacturer for product $i$ at period $t$.

Note that the wholesaler has no prior information about the customer demand. The demand is realized after the ordering decisions are made (See Step 3 in Figure 1). The demand is filled from wholesaler's on-hand inventory. 


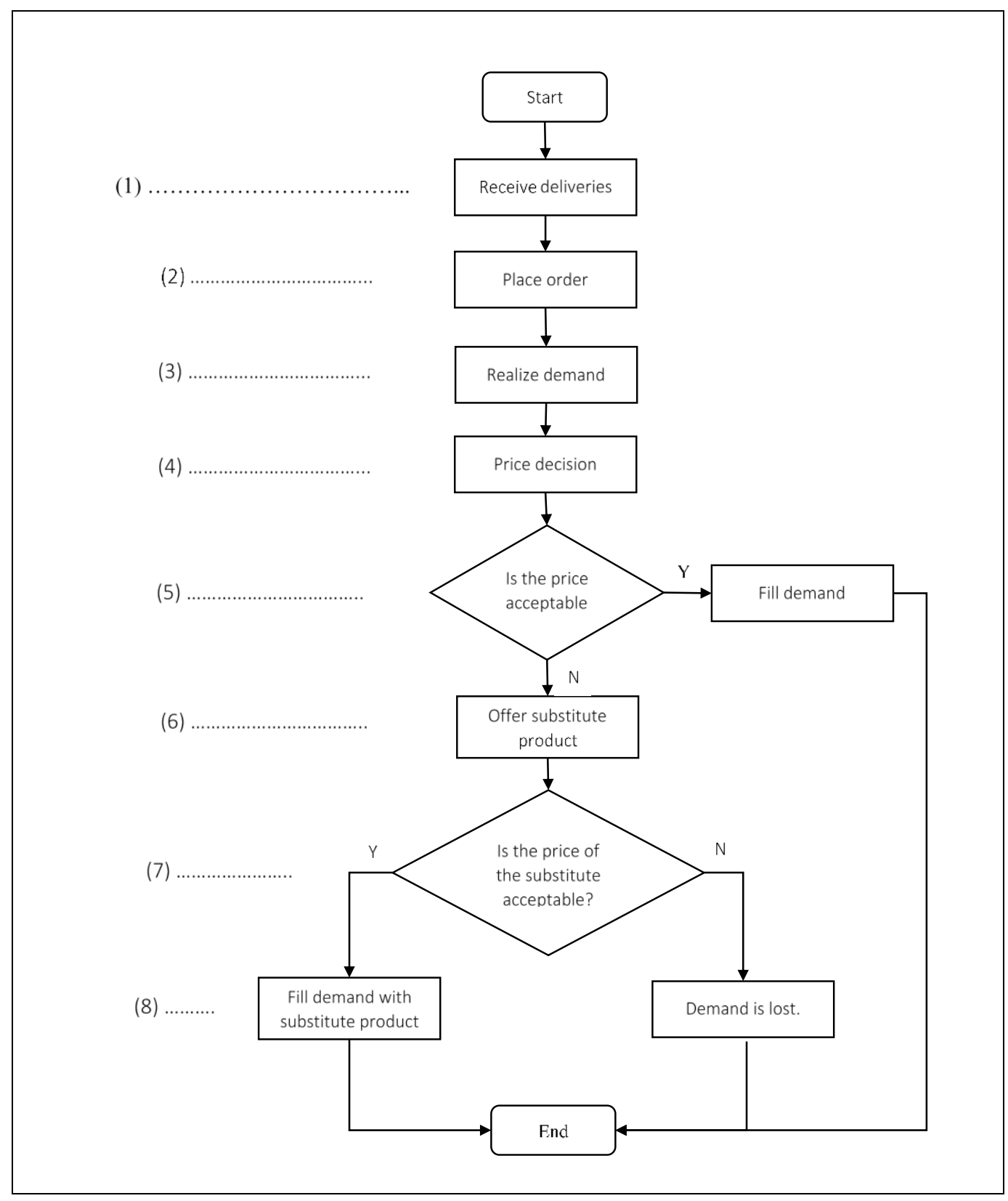

Figure 1. Flowchart for the daily operations.

If the on-hand inventory is insufficient to meet the customer demand, the unfilled portion of the demand is lost. In this case, a shortage cost is incurred. To avoid a possible shortage, the wholesaler adopts a dynamic pricing policy (See Step 4 in Figure 1).

The aim of the dynamic pricing to channel the customer demand from scarce product to other products. The dynamic pricing policy yields high prices in case of low inventory levels. In particular, the price to be offered to the customer is calculated as follows:

$$
p(i, t)=u(i)+\alpha\left[\gamma C(i, t)-I_{b}(i, t)\right]
$$

Where $p(i, t)$ is the price of product $i$ offered at period $t$, $u(i)$ is the unit price of product $i$, and $\alpha$ is the price adjustment parameter. The discrepancy between the desired and actual inventory levels is adjusted by the price adjustment parameter, $\alpha$, and added on the unit price.

If the offered price is not higher than the one that the customer is willing to pay for the product, the demand is filled from the on-hand inventory (Step 5). Otherwise, a substitute product is offered to the customer (Step 6). If the customer is willing to buy the substitute product, the customer demand is filled. Otherwise, the customer demand is lost and a shortage cost is incurred. 
At the end of the period, inventory level for each product is updated as in Eq. 7.

$$
I_{e}(i, t)=I_{b}(i, t)-R(i, t)-R S(j, i, t)
$$

Where $I_{e}(i, t)$ is the inventory level of product $i$ at the end of period $t, R(i, t)$ is the amount of sales of product $i$ at period $t$, and $R S(j, t)$ is the amount of sales product $j$ which substitutes product $i$ at period $t$.

For the problem described above, the critical supply chain performance indicators are sales revenue, holding and shortage costs. Therefore, the objective function of the problem is total annual contribution (TAC) which is calculated by subtracting the annual holding and shortage costs from the annual sales revenue (Eq. 8).

$$
\begin{aligned}
T A C & =\sum_{t=1}^{T} \sum_{i=1}^{N} p(i, t) R(i, t)-\sum_{t=1}^{T} \sum_{i=1}^{N} s(i) L(i, t) \\
& -\sum_{t=1}^{T} \sum_{i=1}^{N} h(i) I_{e}(i, t)+\sum_{t=1}^{T} \sum_{j=1}^{N} p(j, t) R S(j, i, t)
\end{aligned}
$$

Where $T$ is the number of periods in a year, $N$ is the number of products, $h(i)$ is unit holding cost of product $i$ per period, $s(i)$ is shortage cost of product $i$, and $L(i, t)$ is the amount of customer demand for product $i$ which is lost at period $t$.

To maximize $T A C$, optimal values of the exponential smoothing parameter $(\theta)$, the inventory adjustment parameter $(\gamma)$ and the price adjustment parameter $(\alpha)$ should be determined. However, this problem consists of several uncertain parameters and a nonlinear objective function which cannot be addressed by analytical methods efficiently. Therefore, a discrete event system simulation model is developed to specify the parameter values which maximize total annual contribution.

\section{Case study}

The effectiveness of the dynamic pricing strategy in the presence of disruptions is demonstrated on a case study conducted at a company operating in construction materials industry. The company is one of the major suppliers in Turkish paint and insulation sector. The company produces wide range of products such as interior and exterior paints, synthetic paints, water and thermal insulation materials. The company name is kept confidential due to the policy of the company.

This study focuses on a wholesaler associated with the company. The wholesaler distributes the products of the company to the retailers located at Aegean Region of Turkey. The wholesaler aims at high service quality and responsiveness. However, it has confronted a number of disruptions in paint supply which deteriorate the service performance in the last couple of years. The disruptions are originated from the problems in pigment import such as unpredictable fluctuations in exchange rates, and delays during border crossings. As the disruptions are unpredictable, the aim of the wholesaler is to develop strategies to reduce the impact of them.

In this study, effectiveness of the dynamic pricing strategy on the wholesaler performance in presence of disruptions is investigated. In particular, we focus on two best-selling types of exterior paints, namely, product A and B, which have the same characteristics except their color. It is anticipated that the dynamic pricing strategy will channel the demand for the scarce product to other product, and the sales revenue might hereby increase.

\subsection{Simulation model}

The simulation model is developed by using Arena 14.0. The Arena model is provided in the Appendix. For each period, the simulation model initiates the events described in Section 2 at the same order as in Figure 1. Average demands for both products are the same and have similar pattern. Demand for each product is modeled by analyzing the historical demand information. To obtain a reliable demand model, the demand data related to sales promotion periods are excluded from the analysis. As a result, it is confirmed that demands for both products follow a normal distribution with mean of 50 and standard deviation of 4 units. Since the demand for each product is sufficiently high and stable, simple exponential smoothing method is employed for the demand forecast.

Sale prices of products are the same and 150 TL per unit. Holding and shortage costs per unit are $50 \mathrm{TL}$ and $200 \mathrm{TL}$, respectively. The dynamic pricing strategy (see Eq. 6) is adapted to the system described above. In this sense, sales and marketing experts classified the retailers into two categories by considering their buying behavior. The retailers belonging to the first category are defined as "Type 1" retailers. Type 1 retailers are willing to pay for the desired product with a price at most $15 \%$ higher than the regular sale price. If the increase in sale price of the desired product is higher than $15 \%$, a Type 1 retailer will not purchase the product and the demand will be lost. On the other hand, Type 2 retailers are willing to buy the substitute product if the price of the desired product increases by a rate more than $15 \%$. However, the price of the substitute product is increased by a rate more than $5 \%$, the Type 2 demand will be lost. Sales and marketing experts agree that the portions of Type 1 and Type 2 customers are approximately $40 \%$ and $60 \%$, respectively.

The manufacturer's daily shipment capacity is 300 units for each product. However, the past experiences have shown that the shipment capacity is vulnerable against disruptions. Therefore, the developed simulation model consists of a disruption model which calculates the manufacturers' shipment capacity levels for each period. The proposed disruption model is explained subsequently.

\subsubsection{Disruption model}

The disruption model developed in this study is illustrated in Figure 2. As soon as the disruptive event occurs, the manufacturer's shipment capacity decreases by the disruption intensity $(\beta)$. The shipment capacity remains constant until the recovery plans are developed. This phase is described as the stagnation phase. As soon as the recovery plans are implemented, the stagnation phase is over and the recovery phase begins. It is assumed that the capacity recovers linearly during the recovery phase. Moreover, the length of stagnation and recovery phases ar linearly dependent to the disruption intensity $(\beta)$. The proposed disruption model ensures that severe disruptions last for a long time and it is difficult to recover from them. According to the developed disruption model, the ending time of the stagnation $\left(t_{s}\right)$ and recovery $\left(t_{r}\right.$ ) phases are derived as in the following: 


$$
\begin{aligned}
& t_{s}=t_{0}+\delta \beta \\
& t_{r}=t_{0}+\rho \beta
\end{aligned}
$$

Where $\delta$ and $\rho$ are stagnation and recovery factors.

Since there are limited data related to past disruptions, parameters of the disruption model are specified by consulting the managers of the wholesaler. The disruptions are independent. The time between two disruptions is generated from a normal distribution with mean of 90 and standard deviation of 5 days. In the simulation model, as soon as a disruption is initiated, its intensity $(\beta)$ is generated from a normal distribution with mean of $90 \%$ and standard deviation of $0.5 \%$. Stagnation $(\delta)$ and recovery factors $(\rho)$ are specified as 3 and 4 , respectively.

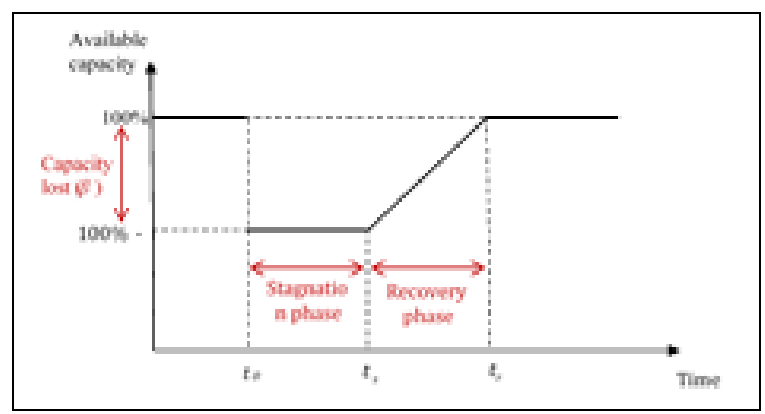

Figure 2. The disruption model.

\subsubsection{Simulation model setting}

The developed simulation model is highly complex and has several uncertain parameters. Therefore, the reliability of the simulation outputs is difficult to attain. To ensure the reliability, the performance is measured only for the periods in which the system is in steady-state. To eliminate the effects of initial conditions on output statistics, a warm-up period is specified. The warm-up period is identified as 100 days by observing the inventory levels of the products. Moreover, the model is run for 3000 days, and the performance values for each year are averaged to obtain a unique performance value. Furthermore, the simulation model is replicated for five times to ensure the reliability of the results. Furthermore, the values for the exponential smoothing $(\theta)$, the inventory adjustment $(\gamma)$ and the price adjustment $(\alpha)$ parameters that maximizes TAC (Eq. 8) are determined by OptQuest for Arena.

\section{Computational study}

To demonstrate the effectiveness of the dynamic pricing strategy, the results obtained from the developed model are compared with those from a simulation model without dynamic pricing. The second simulation model represents the current condition of the system. In this model, the wholesaler adopts base sale price and does not change it in any way. Hereafter, this model will be called as "static pricing model".

In particular, the same parameter values may not guarantee the best result for both models. In this sense, the best parameter values for each model should be determined independently. Therefore, the best values for the exponential smoothing $(\theta)$, the inventory adjustment $(\gamma)$ and the price adjustment $(\alpha)$ parameters are specified by employing
OptQuest for Arena to each model. The results presented in this section have been obtained with the best parameter values.

The results obtained from the simulation models are presented in Table 1. It is clear that dynamic pricing strategy increases TAC by $21 \%$ without a significant change in $\gamma$ and $\theta$. Moreover, the components of TAC are given in Table 2. As one can see from Table 2, dynamic pricing increases the sales revenue and reduces the shortage cost while increasing the holding cost slightly. In particular, the small increase in the holding cost originates from the increase in sales. The dynamic pricing channels the demand for the scarce product to the substitute product. In this case, the sales of the substitute product increase. Consequently, the system tends to hold more stock to fill higher demand. Still, the increase in holding cost is compensated by the decrease in shortage cost and the increase in sales revenue. As a result, the dynamic pricing strategy yields higher TAC. The results reveal that dynamic pricing strategy is effective in protecting the performance during disruptions.

\begin{tabular}{|c|c|c|c|c|}
\hline & $\alpha$ & $\gamma$ & $\theta$ & $T A C$ \\
\hline Dynamic pricing & 0.27 & 2.69 & 0.03 & $2,498,400$ \\
\hline Static pricing & NA & 2.66 & 0.03 & $2,059,600$ \\
\hline \multicolumn{5}{|c|}{ Table 2 . The components of $T A C$. } \\
\hline & $\begin{array}{c}\text { Sales } \\
\text { revenue }\end{array}$ & \multicolumn{2}{|c|}{$\begin{array}{c}\text { Holding } \\
\text { cost }\end{array}$} & $\begin{array}{c}\text { Shortage } \\
\text { cost }\end{array}$ \\
\hline $\begin{array}{c}\text { Dynamic } \\
\text { pricing }\end{array}$ & $5,732,000$ & \multicolumn{2}{|c|}{$3,049,100$} & 184,590 \\
\hline Static pricing & $5,252,400$ & \multicolumn{2}{|c|}{$2,992,800$} & 200,200 \\
\hline
\end{tabular}

Table 1. The simulation results.

\subsection{The alternative disruption scenarios}

In this study, the parameters of the disruption model are determined by consulting the managers of the wholesaler. Since the parameters are specified by imprecise judgments, it is worthwhile to investigate the results obtained for alternative disruption scenarios. In this sense, two alternative disruption scenarios, namely "long disruptions" and "less severe disruptions", are defined. The parameters for the disruption scenarios considered in this study are provided in Table 3. Long disruptions scenario differs from the base scenario in stagnation $(\delta)$ and recovery $(\rho)$ factors. In this scenario, stagnation and recovery phases are longer. In the less severe disruptions scenario, disruptions are more frequent but their severity is relatively low. In this scenario, the stagnation and recovery factors are the same as those in the base scenario.

Table 3. The alternative disruption scenarios.

\begin{tabular}{lcccc}
\hline $\begin{array}{c}\text { Disruption } \\
\text { scenario }\end{array}$ & $\begin{array}{c}\text { Inter- } \\
\text { disruption } \\
\text { time }\end{array}$ & $\beta$ & $\delta$ & $\rho$ \\
\hline Base scenario & $\mathrm{N}(90,5)$ & $\mathrm{N}(90 \%, 0,5 \%)$ & 3 & 4 \\
Long disruptions & $\mathrm{N}(90,5)$ & $\mathrm{N}(90 \%, 0.5 \%)$ & 5 & 7 \\
Less severe & $\mathrm{N}(50,5)$ & $\mathrm{N}(50 \%, 0.5 \%)$ & 3 & 4 \\
disruptions & & & & \\
\hline
\end{tabular}

TAC values, which are obtained for alternative disruption scenarios, are presented in Table 4. As expected, TAC is relatively low in case of long disruptions while it is high in that of less severe disruptions. The results confirm that dynamic pricing yields higher $T A C$ than static pricing in all scenarios. In 
particular, dynamic pricing is relatively less effective in long disruptions scenario but it still improves $T A C$ by $18 \%$. In order to ensure a high protection level against long disruptions, the dynamic pricing strategy may be combined with a back-up supplier strategy.

Table 4. Results obtained for alternative disruption scenarios.

\begin{tabular}{ccc}
\hline Disruption scenario & Dynamic pricing & Static pricing \\
\hline Base scenario & $2,498,400$ & $2,059,600$ \\
Long disruptions & $2,358,000$ & $1,983,900$ \\
Less severe disruptions & $2,677,900$ & $2,212,900$ \\
\hline
\end{tabular}

\subsection{The impact of retailer purchase behavior}

The purchase behavior of the retailers may have significant impact on the success of dynamic pricing strategy. In particular, Type 1 retailers are more conservative in purchasing the substitute product than Type 2 retailers. Therefore, the proportion of Type 1 retailers may affect the success of dynamic pricing strategy. In this sense, additional analysis is performed for different proportions of Type 1 retailers. The obtained results are given in Table 5.

Table 5. The results obtained for different proportions of Type 1 customers.

\begin{tabular}{cc}
\hline Proportion of Type 1 retailers & $T A C$ \\
\hline $20 \%$ & $2,512,400$ \\
$40 \%$ (Base case) & $2,498,400$ \\
$60 \%$ & $2,447,200$ \\
\hline
\end{tabular}

As expected, the performance increases as the proportion of Type 1 customer decreases, and diminishes otherwise. Still, TAC values presented in Table 5 are higher than those obtained for the static pricing case (see Table 1).

\section{Conclusion}

In this study, we consider a supply chain planning problem with disruptions. In this context, a dynamic pricing mechanism is developed to prevent possible stock-outs during disruptions. The effectiveness of the proposed dynamic pricing mechanism is analyzed by using a simulation model. In particular, the optimal values for pricing and inventory control parameters are identified by a simulation-based optimization approach. The proposed pricing approach is implemented to a real-world supply chain. The results reveal the effectiveness of the dynamic pricing policy. Additional analyses for alternative disruption and customer purchase behavior scenarios confirm the applicability of the proposed pricing policy to different supply chain systems. Further effort will focus on the application of the proposed pricing policy to a multi-echelon supply chain. Moreover, the present work can be extended with a non-linear disruption model. Furthermore, combining information sharing strategies with dynamic pricing is a promising future research direction.

\section{References}

[1] Melnyk S, Rodrigues A, Ragatz G. Using Simulation to Investigate Supply Chain Disruptions. In: Zsidisin G, Ritchie B, Editors: Supply Chain Risk. International Series in Operations Research \& Management Science. 124, Springer US; p. 103-22, 2009.

[2] Schmitt AJ, Sun SA, Snyder LV, Shen Z-JM. "Centralization versus decentralization: Risk pooling, risk diversification, and supply chain disruptions". Omega, 52, 201-212, 2015.

[3] Sawik T. "Selection of supply portfolio under disruption risks." Omega, 39(2), 194-208, 2011.
[4] Schmitt TG, Kumar S, Stecke KE, Glover FW, Ehlen MA. "Mitigating disruptions in a multi-echelon supply chain using adaptive ordering". Omega, 68, 185-198, 2017.

[5] Schmitt AJ, Singh M. "A quantitative analysis of disruption risk in a multi-echelon supply Chain". International Journal of Production Economics, 139(1), 22-32, 2012.

[6] Snyder LV, Atan Z, Peng P, Rong Y, Schmitt AJ, Sinsoysal B. "OR/MS models for supply chain disruptions: A review". IIE Transactions, 48(2), 89-109, 2016.

[7] Ivanov D, Dolgui A, Sokolov B, Ivanova M. "Literature review on disruption recovery in the supply chain". International Journal of Production Research, 55(20), 6158-6174, 2017.

[8] Hosseini S, Ivanov D, Dolgui A. "Review of quantitative methods for supply chain resilience analysis". Transportation Research Part E: Logistics and Transportation Review, 125, 285-307, 2019.

[9] Veverka M. "A DRAM shame”. Barron's, October. 25, 115, 1999.

[10] Tang CS. "Perspectives in supply chain risk management." International Journal of Production Economics, 103(2), 451-488, 2006.

[11] Zhu SX. "Dynamic replenishment, production, and pricing decisions, in the face of supply disruption and random price-sensitive demand". International Journal of Production Economics, 146(2), 612-619, 2013.

[12] Gong X, Chao X, Zheng S. "Dynamic pricing and inventory management with dual suppliers of different lead times and disruption risks". Production and Operations Management, 23(12), 2058-2074, 2014.

[13] Huang H, He Y, Li D. "Pricing and inventory decisions in the food supply chain with production disruption and controllable deterioration". Journal of Cleaner Production, 180, 280-296, 2018.

[14] Ghomi-Avili M, Naeini SGJ, Tavakkoli-Moghaddam R, Jabbarzadeh A. "A fuzzy pricing model for a green competitive closed-loop supply chain network design in the presence of disruptions". Journal of Cleaner Production, 188, 425-442, 2018.

[15] Huang Y, Wang Z. "Demand disruptions, pricing and production decisions in a closed-loop supply chain with technology licensing". Journal of Cleaner Production, 191, 248-260, 2018.

[16] Hosseini-Motlagh SM, Nouri-Harzvili M, Choi TM, Ebrahimi S. "Reverse supply chain systems optimization with dual channel and demand disruptions: Sustainability, CSR investment and pricing coordination". Information Sciences, 503, 606-634, 2019.

[17] Hou YT, Huo JZ, Chu F. "An Integrated Problem of-Hub Location and Revenue Management with Multiple Capacity Levels under Disruptions". Journal of Advanced Transportation,Doi:10.1155/2019/1812543, 2019.

[18] Rahmani K, Yavari M. "Pricing policies for a dual-channel green supply chain under demand disruptions". Computers \& Industrial Engineering, 127, 493-510, 2019.

[19] Bugert N, Lasch R. "Effectiveness of responsive pricing in the face of supply chain disruptions". Computers \& Industrial Engineering, 124, 304-315, 2018.

[20] Wilson MC. "The impact of transportation disruptions on supply chain performance". Transportation Research Part E: Logistics and Transportation Review, 43(4), 295-320, 2007. 


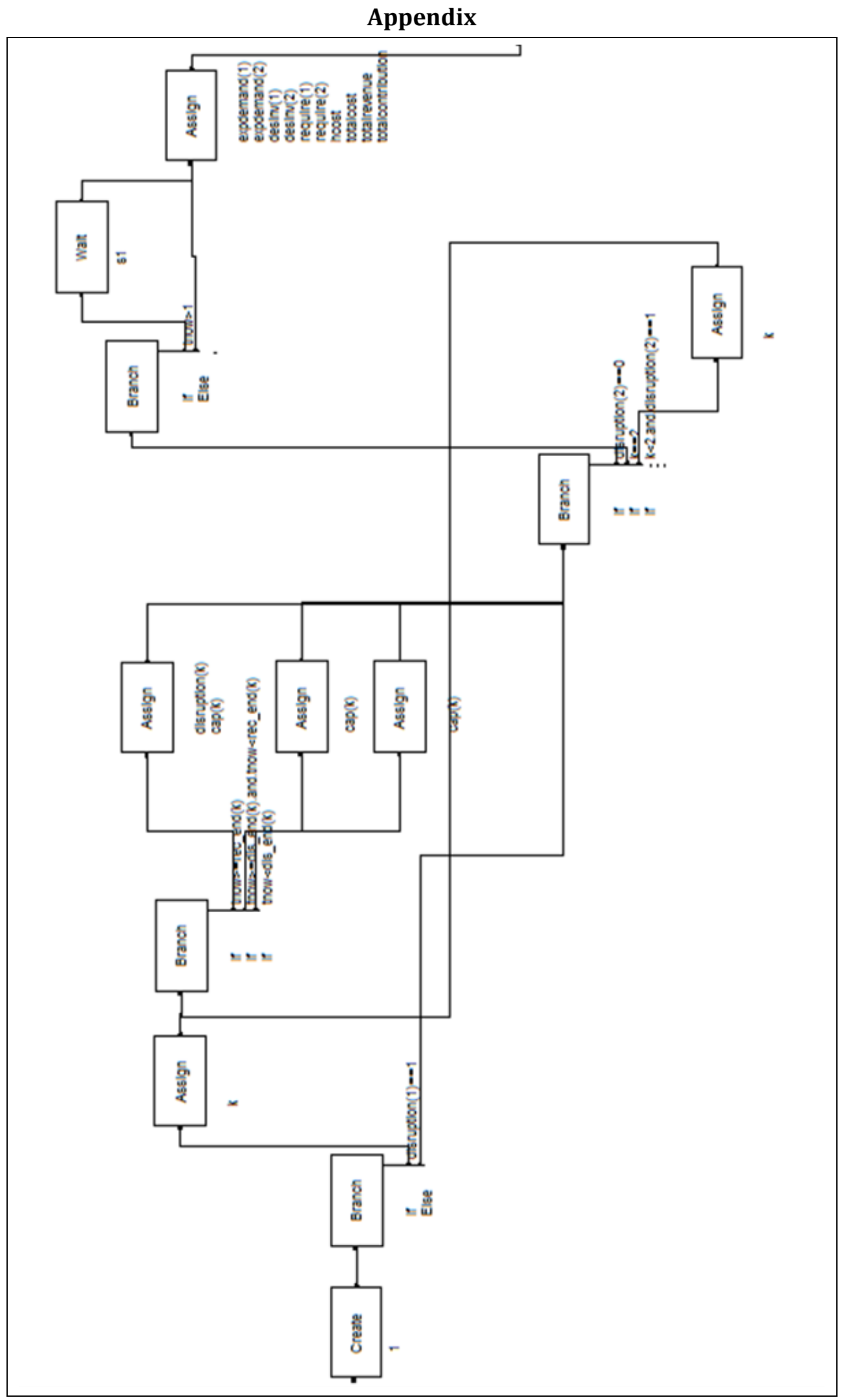

Figure A. 1. The part of the simulation model related to the daily operations of the wholesaler. 


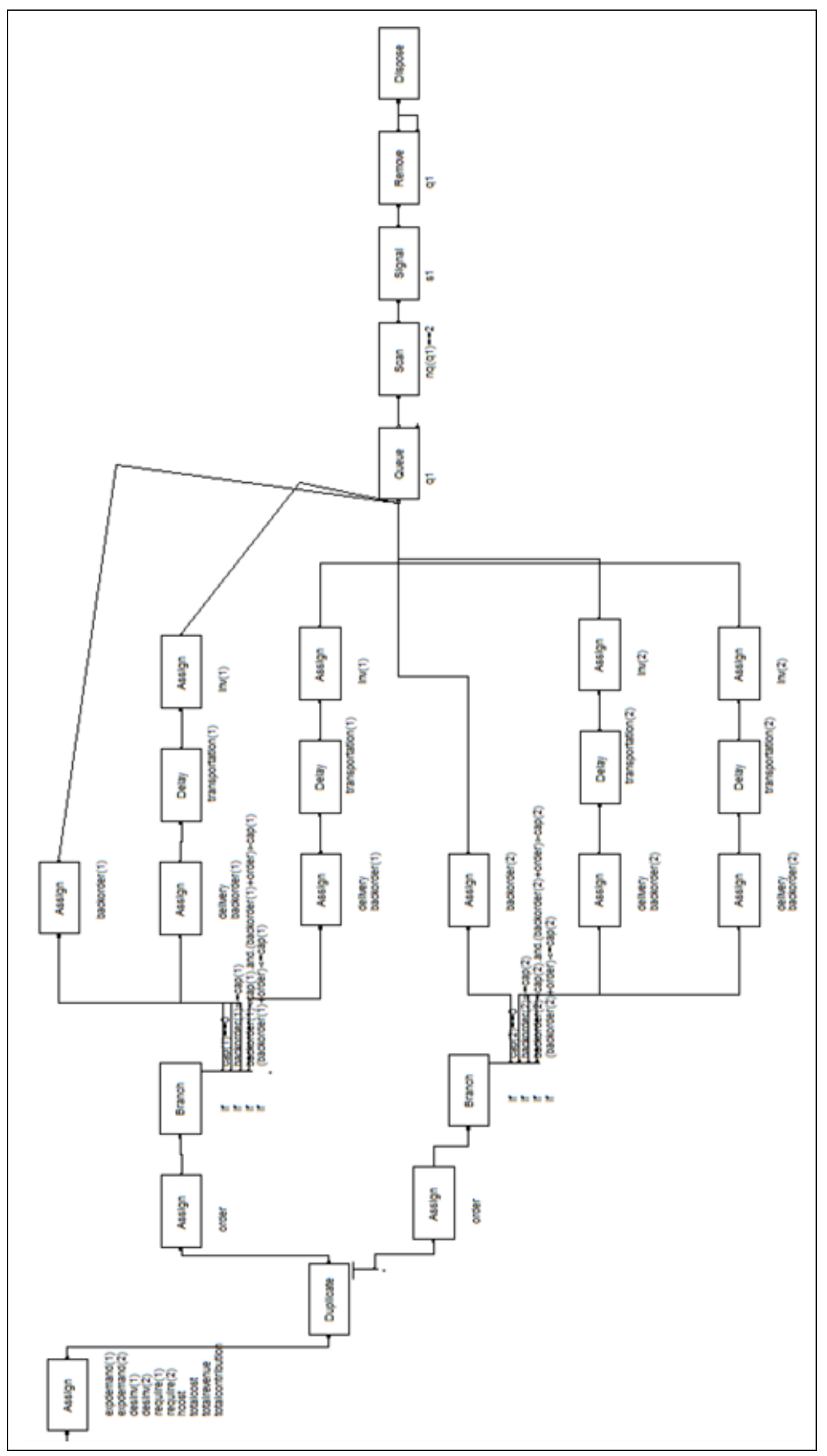

Figure A. 2. The part of the simulation model related to the daily operations of the wholesaler (continued). 


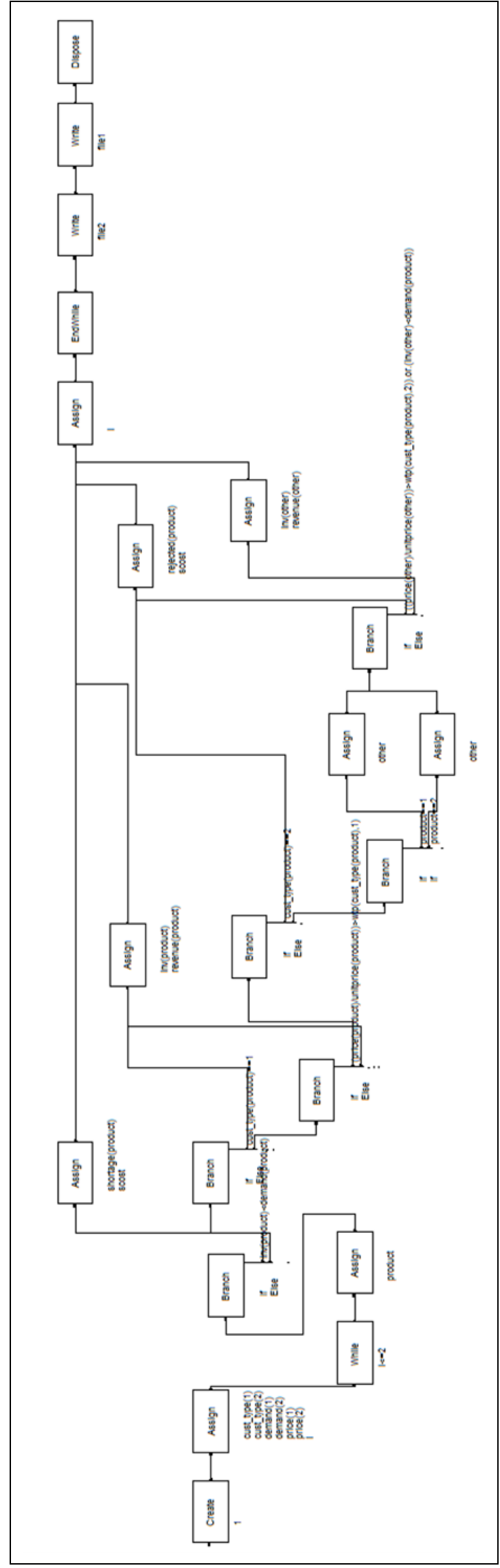

Figure A. 3. The part of the simulation model related to the retailer's demand and purchasing behavior. 


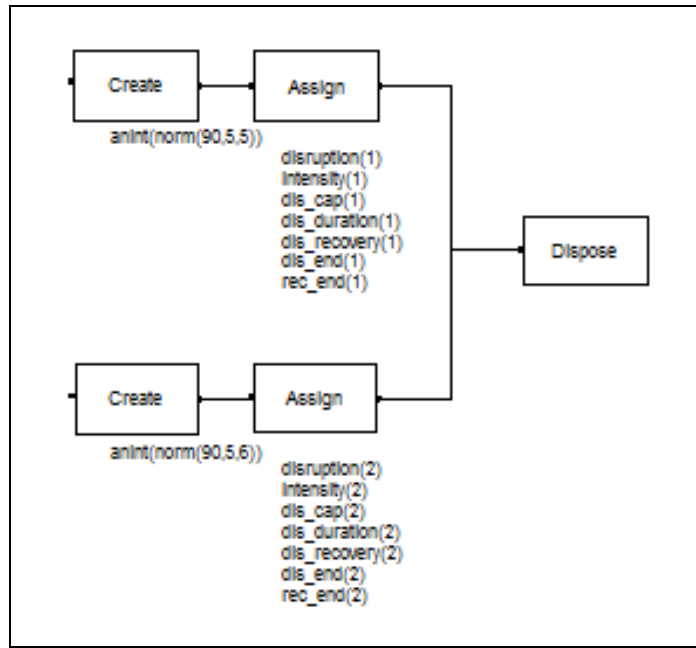

Figure A. 4. The part of the simulation model which generates disruption. 